\title{
Physiological and subjective evaluation of tractor operator workplace
}

\author{
SAUMYA SHUKLA
}

\begin{abstract}
Tractors are the major source of farm power. Tractor driving imposes a lot of physical and mental stress upon the operator. This study was aimed at evaluating the physiological and subjective response of tractor operators while driving a tractor. Five tractor models and three male tractor operators were randomly selected for the study. The physiological evaluation was carried out in terms of heart rate and data were analyzed on the basis of two Factor Completely Randomized Design. The results showed that the effect of tractors on the heart beat was significant but the effect of subjects was found to be nonsignificant. The energy expenditure rate was ranged from 6.34 to $10.94 \mathrm{kJmin}^{-1}$; indicating that in some tractors, operation requires a lot of physical effort. Rated Perceive Exertion scores were also in match with the physiological evaluation. The results call upon the manufactures to ergonomically design the tractor workplace to make it more comfortable for the operator.
\end{abstract}

KEY WORDS : Tractor, Operator, Heart rate, Energy expenditure rate, Rated perceive exertion score

How to cite this Article : Shukla, Saumya (2016). Physiological and subjective evaluation of tractor operator workplace. Engg. \& Tech. in India, 7 (1) : 26-32. 